\title{
Vegetation Dynamics on the Tibetan Plateau (1982-2006): An Attribution by Ecohydrological Diagnostics
}

\author{
Danlu CAI, ${ }^{*+}{ }^{+}$Klaus Fraedrich, ${ }^{+}$Frank Sielmann, ${ }^{\#}$ Ling Zhang, ${ }^{+}$ \\ XiUhua Zhu, ${ }^{@}$ SHAN GuO,* AND Yanning GuAN* \\ * Institute of Remote Sensing and Digital Earth, Chinese Academy of Sciences, Beijing, China \\ ${ }^{+}$Max-Planck-Institute for Meteorology, Hamburg, Germany \\ \# Meteorological Institute, University of Hamburg, Hamburg, Germany \\ ${ }^{\circledR}$ KlimaCampus, Hamburg University, Hamburg, Germany
}

(Manuscript received 10 October 2014, in final form 22 January 2015)

\begin{abstract}
Vegetation greenness distributions [based on remote sensing normalized difference vegetation index (NDVI)] and their change are analyzed as functional vegetation-climate relations in a two-dimensional ecohydrological state space spanned by surface flux ratios of energy excess ( $U$; loss by sensible heat $H$ over supply by net radiation $N$ ) versus water excess $(W$; loss by discharge Ro over gain by precipitation $P)$. An ecohydrological ansatz attributes state change trajectories in $(U, W)$ space to external (or climate) and internal (or anthropogenic) causes jointly with vegetation greenness interpreted as an active tracer. Selecting the Tibetan Plateau with its complex topographic, climate, and vegetation conditions as target area, ERA-Interim weather data link geographic and $(U, W)$ state space, into which local remote sensing Global Inventory Modeling and Mapping Studies (GIMMS) data (NDVI) are embedded; a first and second period (1982-93 and 1994-2006) are chosen for change attribution analysis. The study revealed the following results: 1) State space statistics are characterized by a bimodal distribution with two distinct geobotanic regimes (semidesert and steppe) of low and moderate vegetation greenness separated by gaps at aridity $D \sim 2$ (net radiation over precipitation) and greenness NDVI $\sim 0.3$.2) Changes between the first and second period are attributed to external (about 70\%) and internal (30\%) processes. 3) Attribution conditioned joint distributions of NDVI (and its change) show 38.2\% decreasing (61.8\% increasing) area cover with low (moderate) greenness while high greenness areas are slightly reduced. 4) Water surplus regions benefit most from climate change (showing vegetation greenness growth) while the energy surplus change is ambiguous, because ecohydrological diagnostics attributes high mountainous regions (such as the Himalayas) as internal without considering the heat storage deficit due to increasing vegetation.
\end{abstract}

\section{Introduction}

Recent climatic change, coupled to timing and duration of the warm season and associated with snow-free and nonfrozen ground conditions (Goulden et al. 1998; Nemani et al. 2003), has enhanced plant dynamics in the Northern Hemisphere by shifting seasonal warmth to earlier in spring and later in autumn (Barichivich et al. 2013; Burrows et al. 2011), reducing snow-cover duration and thus extending the length of the vegetation growing season (Keeling et al. 1996; Myneni et al. 1997). In these regions, phenology controls the seasonal onset

Corresponding author address: Yanning Guan, Institute of Remote Sensing and Digital Earth, Chinese Academy of Sciences, Beigen West Road \#1, Beijing 100101, China.

E-mail: guanyn@radi.ac.cn and ending of the carbon uptake period, thereby directly affecting net ecosystem carbon balance (Barr et al. 2009; Goulden et al. 1998; Richardson et al. 2010; Cong et al. 2013) and the exchange of water and energy with the atmosphere (Peñuelas et al. 2009).

Both climate change and anthropogenic activities are known to have an impact on plant dynamics ( $\mathrm{Hu}$ et al. 2012; Serra et al. 2008; Wang et al. 2008; Piao et al. 2003) and hence on the exchange of water and energy with atmosphere (Renner et al. 2012; Tomer and Schilling 2009; Wang and Hejazi 2011; Zhang et al. 2001). However, a comprehensive analysis of the impact of climate change and anthropogenic activities on plant dynamics has not been analyzed in northern high altitudes applying the rainfall-runoff chain framework. The coupled waterenergy budget and separation of respective variables provides an ecohydrological diagnostics that, based on 
results from long-term watershed experiments, can attribute total change to impacts of external or climate and internal or land-use/watershed change (Tomer and Schilling 2009).

The Tibetan Plateau, defined as the center of the "Third Pole," is highly sensitive to climate change and to anthropogenic activities (Hu et al. 2012; Wang et al. 2008; Kang et al. 2010). Therefore, this paper visits two periods attributing observed changes to external or climate impact or to internal or anthropogenic activities employing an attribution diagnostics. After introducing this attribution scheme in state space (section 2; see Fig. 1) we continue (section 3) with a first presentation of the datasets in geographical space (see Fig. 2) and their corresponding state space histograms (see Fig. 3). Applying the attribution scheme to the observed dynamics of change (see Figs. 4) we present the results in geographical space (see Figs. $5 \mathrm{a}-\mathrm{c}$ ), which are supplemented by conditionally attributed changes scaled down to the normalized difference vegetation index (NDVI) vegetation scale (see Figs. 5d-g). Conclusions and an outlook (section 4) elucidate the biophysical underpinning and discuss the relevance of attribution analysis of change for the resilience of vegetation as part of the regional climate regime.

\section{Ecohydrological diagnostics in a surface climate state space}

The rainfall-runoff chain receives a total supply of water and energy: That is rainfall $P$ (balanced by runoff Ro and evapotranspiration $E$ ) and net radiation $N$ or potential evapotranspiration, which, representing a water demand, is balanced by sensible heat flux $H$ and evapotranspiration $E$ (energy flux units are in water flux equivalents, $\left.\mathrm{m} \mathrm{yr}^{-1}\right)$ :

$$
\begin{aligned}
P & =\mathrm{Ro}+E \text { and } \\
N & =H+E .
\end{aligned}
$$

In equilibrium, water and energy supply, $P$ and $N$, provide the external or climate forcing, while partitioning of water and energy fluxes, Ro plus $E$ and also $E$ plus $H$, depends on internal processes.

\section{a. The ecohydrological $(U, W)$ state space}

Surface climates are conveniently analyzed in terms of flux ratios (Budyko 1974) of which the aridity, $D=N / P$, combines energy and water supply and plays an important role characterizing geobotanical states. However, a separation of energy and water fluxes is required to characterize the ecohydrological environment (Milne et al. 2002): 1) relative excess water $W=\mathrm{Ro} / P$ is the portion of water supply not being used by the ecosystem and thus available for geomorphological formation and 2) relative excess energy $U=H / N$ is the portion of energy supply not being used for evapotranspiration:

$$
\begin{aligned}
U & =H / N=1-E / N \quad \text { and } \\
W & =\mathrm{Ro} / P=1-E / P .
\end{aligned}
$$

Thus $(U, W)$ coordinates span an ecohydrological state space of surface variables "reflecting the coupling of biotic and abiotic processes in the landscape" (watershed) in terms of "energy available for photosynthesis $(U)$ and water available for terrain formation $(W)$ " by separating energy from water flux-related excesses (Milne et al. 2002). Usually both flux ratios are bound within the interval $(0,1]$ and known as water and energy limits of the rainfall-runoff chain.

Figure 1 displays the $(U, W)$ plane showing lines $U=$ $1+(W-1) / D$ through the $(U=1, W=1)$ point, whose slopes represent (inverse) aridity ratios:

$$
D=N / P=(1-W) /(1-U) .
$$

They range from $D<1$ characterizing wet energy limited climates to $D>1$ for dry water limited regimes, separated by the main diagonal $(D=1)$. In Budyko's (1974) geobotanical framework aridity provides a quantitative measure of the climate-vegetation relation with tundra, $D<1 / 3$; forests, $1 / 3<D<1$; steppe and savanna, $1<D<2.0$; semidesert, $2.0<D<3.0$; and desert, $3.0<D$.

\section{b. Changes in $(U, W)$ state space: An attribution analysis}

Ecohydrological analysis in the $(U, W)$ plane is based on long-term average states balancing the water and energy fluxes coupling soil, vegetation, hydromorphologic, and atmospheric compartments (Milne et al. 2002). States shifting from one (long term) averaging period to the next can be traced [Fig. 1; see also Fig. 2 in Tomer and Schilling (2009)] as pieces of trajectories that, due to coordinates separating water and energy supplies, provide a direct measure of the causes of change induced by external (climate) forcing and internal (anthropogenic) processes:

1) Change vectors (arrows) represent pieces of trajectories which indicate ecohydrological shifts between a first and a second period, whose directions range from $0^{\circ}$ to $360^{\circ}$

2) Based on Budyko's aridity index, $D=N / P=1$, separating energy $(N<P)$ from water limited $(N>P)$ regimes, change vectors heading from $45^{\circ}$ to $225^{\circ}$ tend toward dryer conditions in the second period, or wetter conditions for reverse directions. 

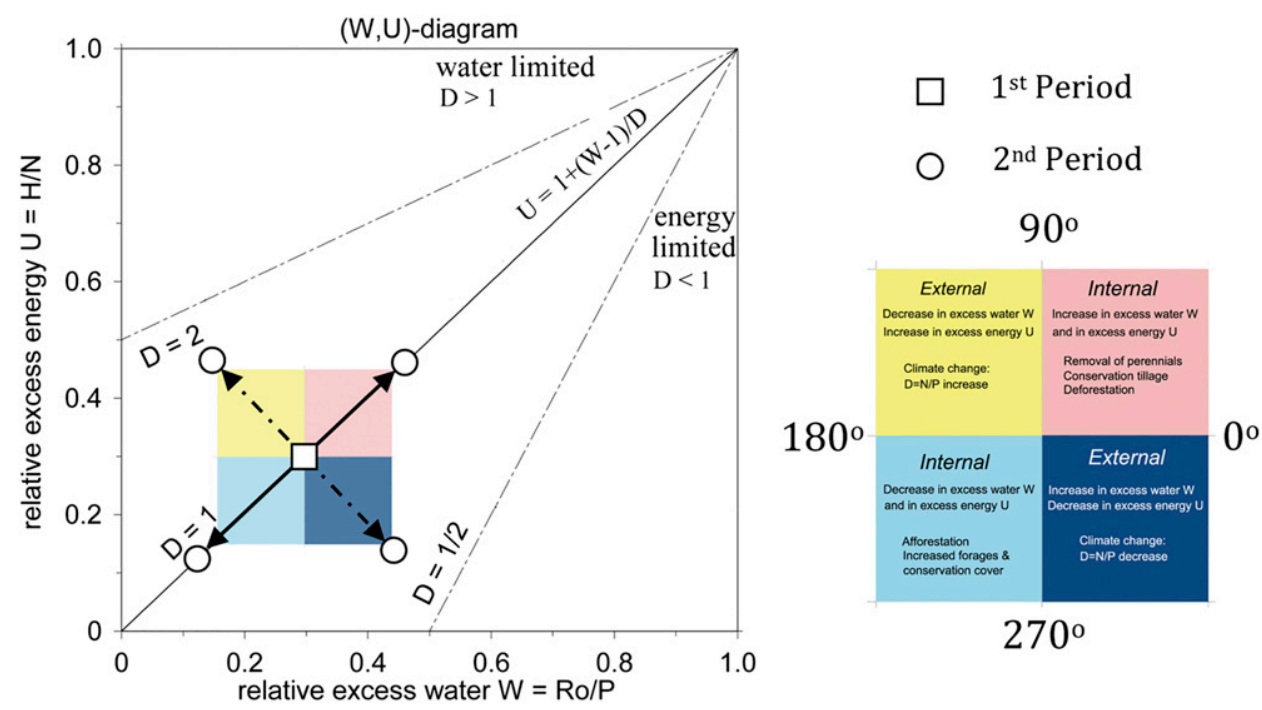

FIG. 1. Ecohydrological states in the $(U, W)$ diagram spanned by relative excess water $W$ (runoff vs precipitation) and energy $U$ (sensible heat flux vs net radiation) with lines of constant dryness $D$ (net radiation vs precipitation). Ecohydrological states are denoted by squares and circles: The reference states (squares) represent the first period, which is followed by subsequent shift to the second period (circles). Directions and lengths of arrows connecting first with second period provide the attribution of change (see text): Trajectories along (across) the main diagonal characterize a change of the internal (external) partitioning.

3) Ecohydrological shifts in $(U, W)$ state space are associated with four conditions of change of relative excess water $W$ and energy $U$ supplies (Fig. 1): both increasing (pink first quadrant: $0^{\circ}-90^{\circ}$ ) or decreasing (light blue third quadrant: $180^{\circ}-270^{\circ}$ ), or increasing $W$ and decreasing $U$ (dark blue fourth quadrant: $270^{\circ}-360^{\circ}$ ) or vice versa (yellow second quadrant: $\left.90^{\circ}-180^{\circ}\right)$.

The attribution model based on trajectories in $(U, W)$ state space is introduced. 1) Assume constant climate forcing ( $P$ and $N$ constant) but evapotranspiration $E$ having changed over time: then, $d U=-d E / N$ and $d W=-d E / P$ represent an internal change in flux partitioning (say $d E$ ) affecting the watershed, such as a change in vegetation or land surface, which results in a deviation from the positive diagonal (Fig. 1, pink first quadrant and light blue third quadrant). 2) On the other hand, assume that $E$ is constant; then $d D>0(<0)$ leads to increasing (or decreasing) $U=1-E / N$ and decreasing (or increasing $W=1-E / P$ ). That is, climateinduced change tends along the negative diagonal toward the yellow second quadrant and dark blue fourth quadrant (see Fig. 1).

\section{Changes on the Tibetan Plateau}

Its complex topography and climate make the Tibetan Plateau sensitive to global change in the past and near future (An et al. 2001; Yao et al. 2006; Duan and Wu
2008; Yang et al. 2011; Zhu et al. 2011; Yao et al. 2012; Zhu et al. 2013) and an ideal target area for ecohydrological diagnostics (see Chen et al. 2014). Before attributing the changes to external and internal causes geographical and state space statistics are presented.

\section{Data and preprocessing}

Both ERA-Interim (Balsamo et al. 2012) and Global Inventory Modeling and Mapping Studies (GIMMS) NDVI (Tucker et al. 2005) datasets are used (1 largescale ERA geographic pixel is approximately equal to 100 small-scale NDVI pixels); for detailed data resampling and energy fluxes conversion to water equivalents, see Cai et al. (2014b). The periods of 1982-93 and 19932006 are suggested by the temporal evolution of mean annual sunshine duration showing high (low) values during the first (second) period (see Fig. 2 of You et al. 2010; You et al. 2013) and by Wang et al. (2015) demonstrating the strong influence of sunshine duration on vegetation dynamics (and NDVI) in Tibet, particularly by recent changes in temperature (Piao et al. 2003) as well as carbon dioxide levels (Richardson et al. 2010; Cong et al. 2013) in the late twentieth century.

\section{1) GeOgRAPHicAl AND CLIMATOLOGicAL SETTING}

Geographical distributions of $(U, W)$ state variables, vegetation greenness, and their related changes are presented first (Fig. 2). The mean water excess $W$ displays a 
Relative excess water

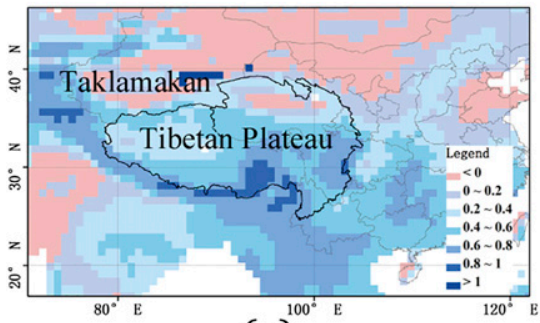

(a)

Relative excess water change

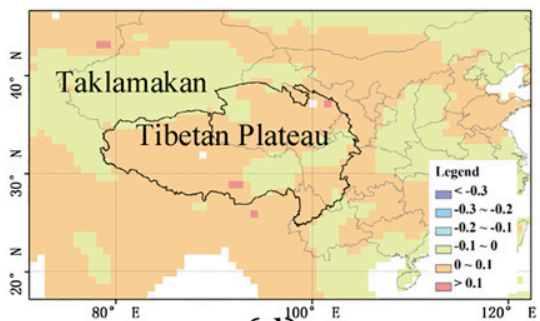

(d)
Relative excess energy

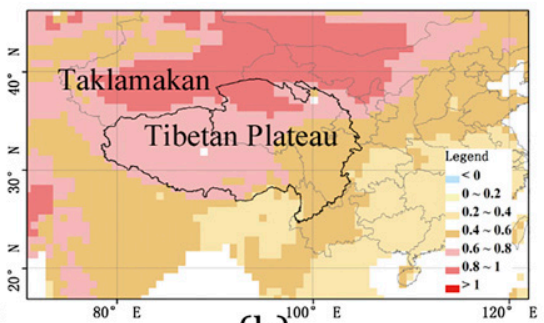

(b)

Relative excess energy change

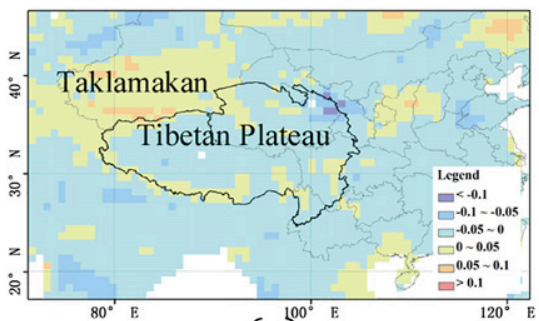

(e)
Vegetation greenness

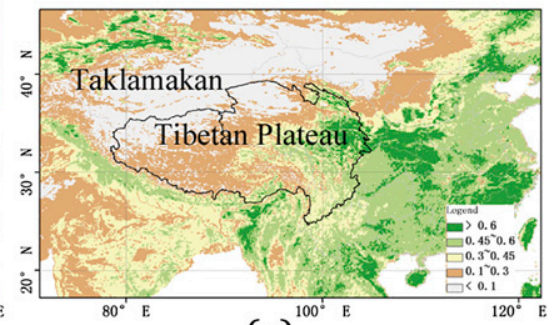

(c)

Vegetation greenness change

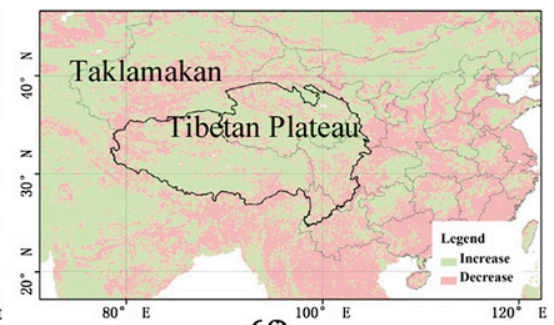

(f)

FIG. 2. Geographical distributions of ecohydrological climate means (1982-2006). (a) Relative excess water $(W=\mathrm{Ro} / P)$. (b) Relative excess energy, the ratio of sensible heat and net radiation $(U=1-E / N)$, from ERA-Interim. (c) Satellite-based vegetation greenness index (NDVI) based on remote sensing data: very low values of NDVI (0.1 and below) correspond to barren areas, sand, or snow; moderate values represent shrub and grassland (0.1-0.3); and high values indicate temperate and tropical rain forests (0.6 and above). Geographical distribution of ecohydrological climate change (second period 1994-2006 minus first 1982-93, e.g., U2 - U1). (d) Relative excess water. (e) Relative excess energy. (f) Satellite-based vegetation-greenness index.

more heterogeneous or random pattern compared to mean energy excess $U$. Vegetation greenness shows a clear west-east separation with very low values $(0.1$ and below) corresponding to barren areas, sand, or snow; low values represent shrub and grassland (0.1-0.3), followed by a moderate transition range $(0.3-0.6)$, to high values, which characterize temperate and tropical rain forests (0.6 and above) (Panday and Ghimire 2012).

These land surface states are presented as frequency (number density) distribution (Fig. 3), whose boundary includes all 373 ERA-Interim area units of the Tibetan Plateau. 1) This is substantiated by NDVI being linearly related to excess energy or water. Despite regional deviations from linearity (Figs. 4c,d), reflecting complex regional soil-vegetation dynamics, NDVI changes can be attributed to $(U, W)$ trajectories (at fixed location) as "active tracers." 2) The mass concentrates in the water limited domain $(D>1)$ with high excess energy $(U>0.5)$. $3)$ It is characterized by bimodality with two preferred geobotanical states of semidesert and steppe separated by aridity $D \sim 2$ and excess energy $U \sim 0.6$.

\section{2) Vegetation in $(U, W)$ state space: Means AND CHANGES}

Projecting the area averaged NDVI onto the $(U, W)$ plane (Figs. 4a,b, smoothed frequencies) shows low, moderate, and high (gray, brown, and green, respectively) vegetation greenness that comprise 235,128 , and 10 pixels in the first period versus 238,121, and 14 in the second. Comparing Figs. $4 \mathrm{a}$ and $4 \mathrm{~b}$ with Figs. $3 \mathrm{c}$ and $3 \mathrm{~d}$ shows that bimodality of Budyko's geobotanic regimes of semidesert or steppe corresponds with low or moderate vegetationgreenness classes. Also, the energy-limited domain, $D<1$, reveals moderate greenness.

Change in $(U, W)$ space is represented by pieces of trajectories; only those are analyzed (Figs. $4 \mathrm{c}, \mathrm{d}$ ) whose components exceed standard deviation of $U$ or $W$ [std $(U)$ or $\operatorname{std}(W)]$; that is, 78 pixels (of 373). Increasing vegetation greenness (50 pixels) accounts for most of the significant changes occurring mainly in water limited regimes $(D \geq 1)$ : semidesert trajectories $(D>2$ and $U>0.6$, low NDVI) tend toward larger wetness with $(\sim 65 \%)$ increasing greenness. Only the southeastern and northwestern parts are dominated by greenness decreasing under wetter conditions (Fig. 2f). Steppe trajectories $(1<D<2)$ change along the $U \sim 0.6$ frequency gap separating low and moderate greenness. That is, increasing steppe greenness depends solely on increasing excess water $W$ and decreasing aridity $D$. Also, there are decreasing vegetation greenness (28 pixels) clusters in both water- and energy-limited regimes $(D<1$ to $1 / 2$ and $D \geq 2)$ in the barely vegetated 

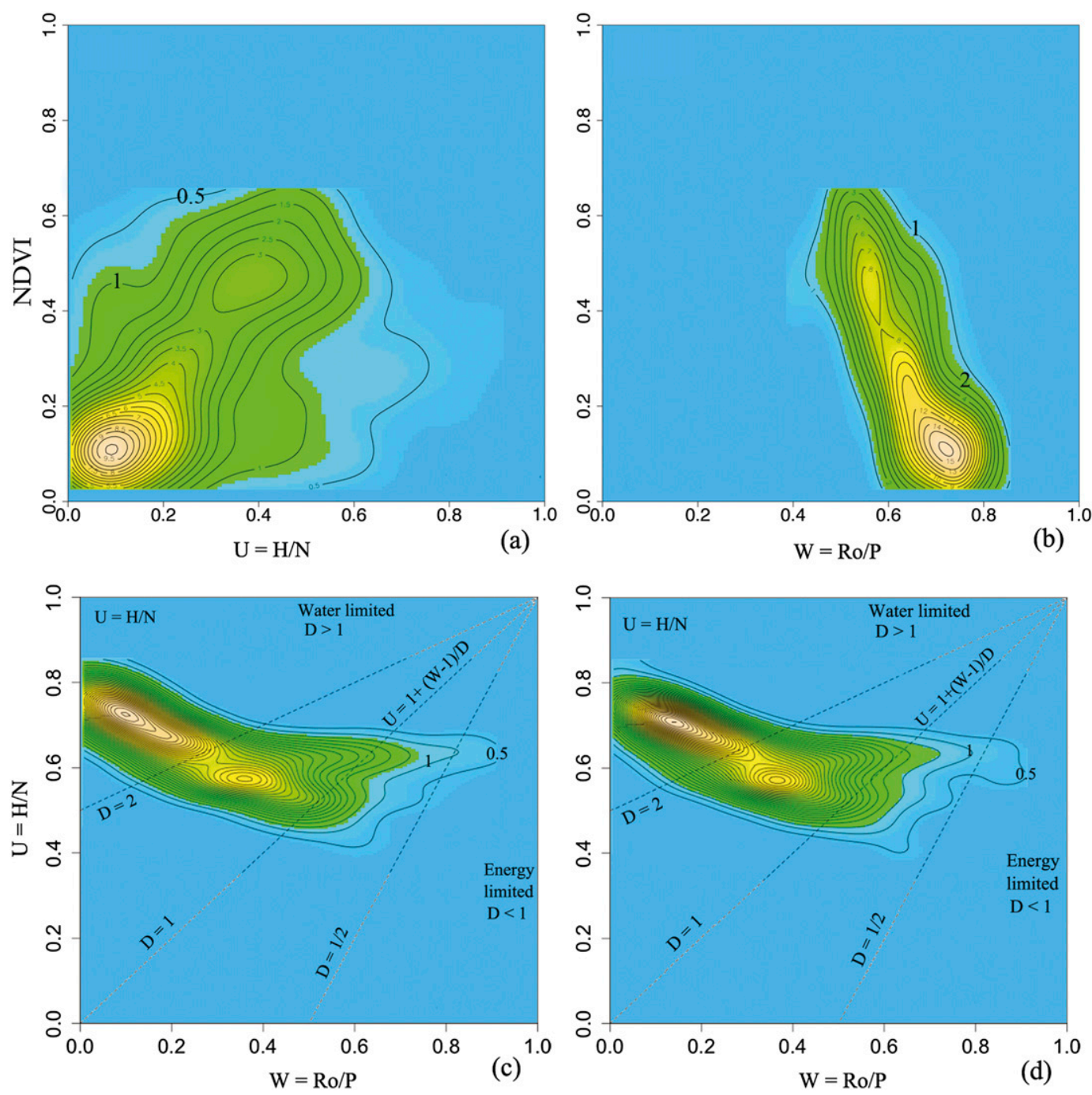

FIG. 3. Frequency distributions of vegetation greenness index (NDVI) on the Tibetan Plateau associated with (a) excess energy $U$ and (b) excess water $W$, and frequency distributions of excess energy and water $(U, W)$ for (c) 1982-93 and (d) 1994-2006; the total land area corresponds to the total number of equal area units. The threshold separating energy-limited from water-limited regimes $(D=1)$ is also included.

northwest and in the well-forested southeastern Tibetan Plateau (Fig. 2c).

\section{3) Attribution of $(U, W)$ Changes}

Regions of change attributed to external and internal causes are partitioned into four quadrants and first displayed geographically (Figs. 5a,b). 1) Changes in Tibet are predominantly affected by external processes (dark blue fourth quadrant: increasing $W$ and decreasing $U$, or decreasing aridity). That is, wet tendencies in Tibet (Figs. 2d,e) control vegetation dynamics in most regions, although overgrazing combined with small mammal outbreaks are considered as primary cause of increased degradation of alpine meadows. 2) Internal (anthropogenic) effects are detected in regions (light blue third quadrant) where vegetation and excess water and energy decrease. A possible cause is related to population density increasing by about half a million to 2616300 from 1990 to 2000 (fifth census in Tibetan autonomous region) with a population density $>2$ persons per square kilometer matching this strip distribution [see Fig. 1 in Wang (2009)].3) Spatial overlap between permafrost and external change-controlled regions (dark blue fourth quadrant) indicates a significant influence matching $\mathrm{Wu}$ et al.'s (2013) conclusion that intensive surface warming (external) is responsible for the concurrent increase in permafrost temperatures on the plateau. 4) Of the $21 \%$ of Tibet affected by significant $(U, W)$ change, $70 \%$ is attributed to external causes (with $46 \%$ increasing vs $24 \%$ decreasing NDVI) and $30 \%$ to internal (15.5\% vs $14.5 \%$; 

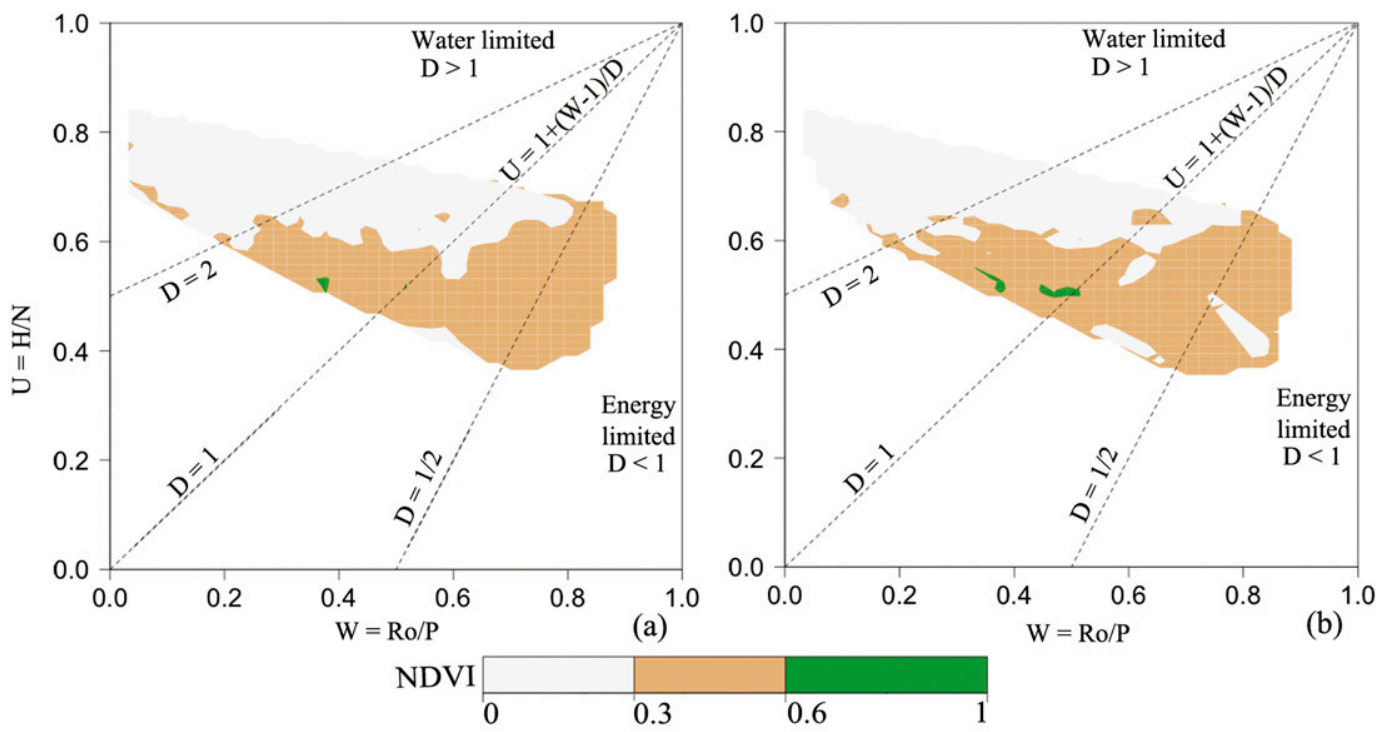

3
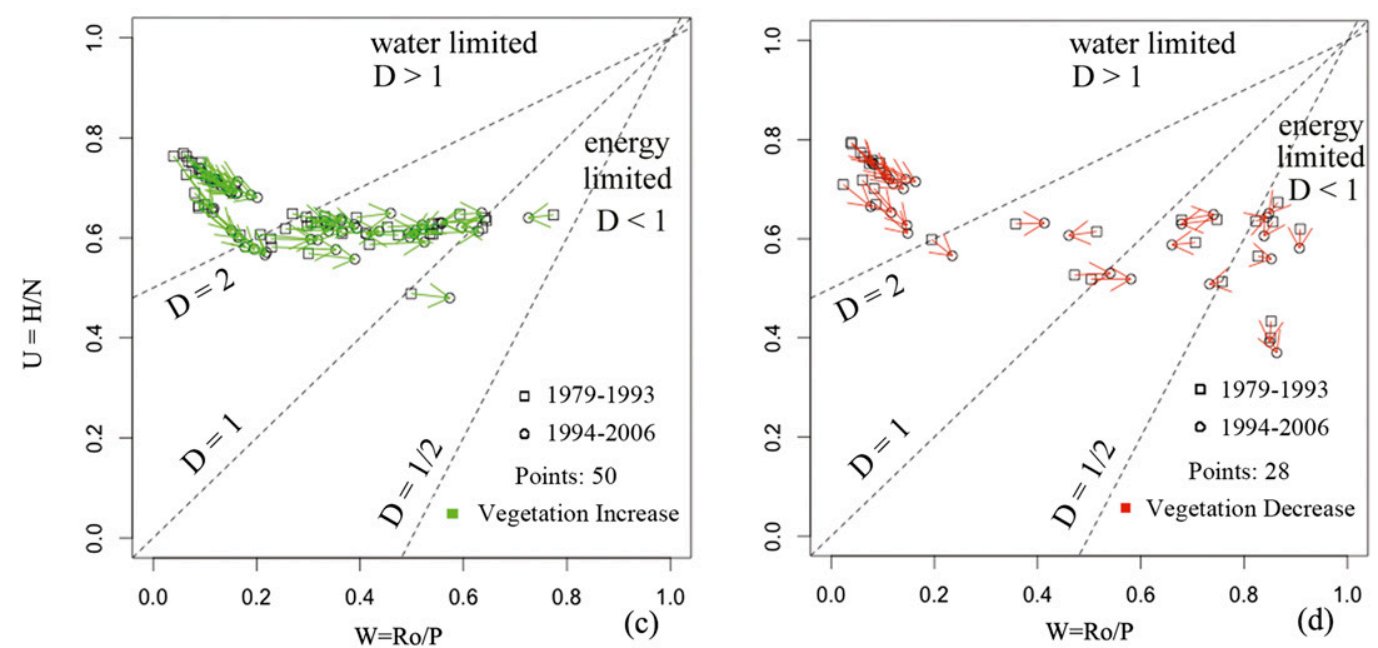

FIG. 4. Frequency distributions of vegetation greenness index (NDVI) and their trajectories in the $(U, W)$ state space (from ERA-Interim): NDVI vegetation in the $(U, W)$ diagram (smoothing by linear interpolation) for (a) 1982-93 and (b) 1994-2006. Trajectories $(U, W)$ changes exceeding $\operatorname{std}(U)$ or $\operatorname{std}(W)$ are shown for regions of (c) increasing (green) and (d) decreasing (red) vegetation greenness. The threshold separating energy-limited from water-limited regimes $(D=1)$ is also included.

for the entire Tibetan Plateau; Table 1). Note that these results refer to large-scale $(U, W)$ changes with related area-averaged NDVI; they compare well with Chen et al. (2014) analyzing the impact of climate change and anthropogenic activities on alpine grassland over Tibet based on a net primary production model for grassland: averaged from 1982 to 2011 , about $68.5 \%$ (31.5\%) of the area of actual grassland change is attributed to a changing climate (human activities).

\section{4) AtTRIBUted NDVI CHANGES:}

\section{A DOWNSCALING ANALYSIS}

Attribution-conditioned joint frequency distributions, which relate future change with vegetation greenness states in GIMMS resolution (Figs. 5d-g), provide the state space interpretation of the geographical patterns (Figs. 5b,c) for regions with significant NDVI change [i.e., exceeding std(NDVI)]:

1) Increasing excess water (Figs. $5 \mathrm{~d}, \mathrm{~g}$ ) is associated with increasing NDVI in most of the regions. The observed NDVI increase may be explained by melting ice or permafrost providing the required moisture supply.

2) Decreasing excess water (Figs. $5 e, f$ ) is associated with decreasing (increasing) high or steppe (low or semidesert) NDVI greenness; locations of NDVI decreasing from initially high level are observed in Cona, Shannan Prefecture, and Medog, Nyingchi Prefecture. 


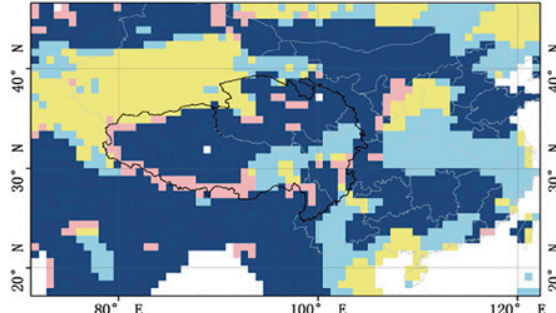

(a)

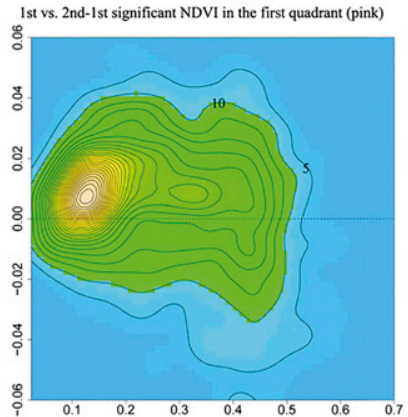

(d)

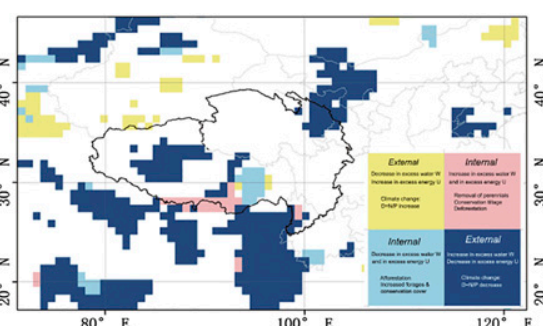

(b)

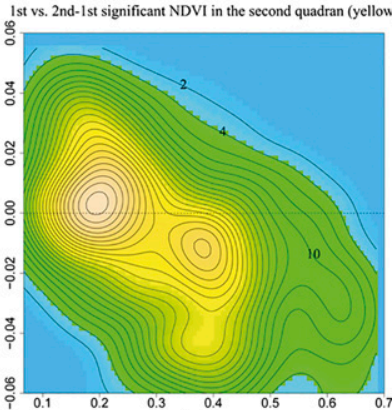

(e)

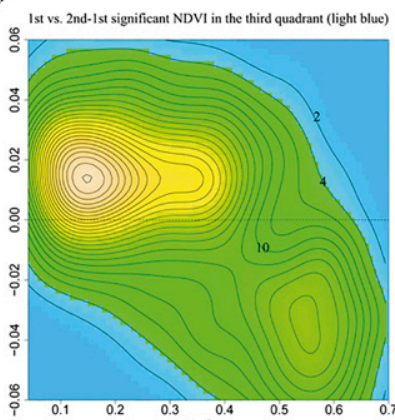

(f)

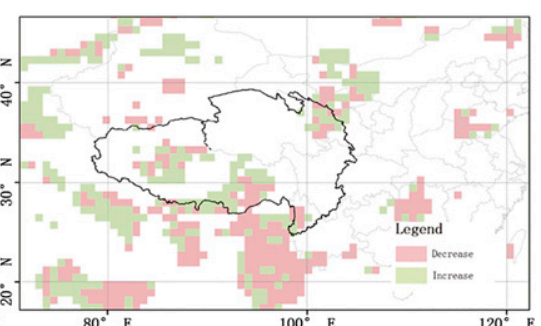

(c)

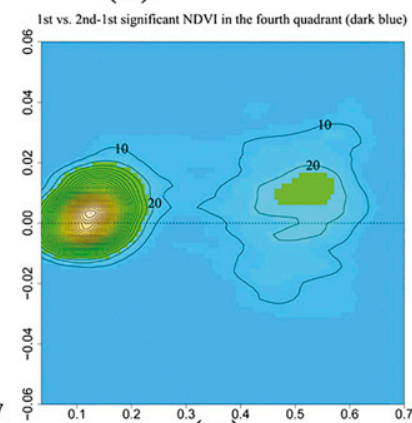

(g)

FIG. 5. Distributions of attribution classes of ecohydrological change on the Tibetan Plateau separating internal from external causes: Geographical distributions of (a) all areas of $(U, W)$ change, (b) significant ones exceeding std $(U)$ or std( $(W)$, and (c) its related NDVI change (ERA scale). Attribution class conditioned joint frequency distribution of NDVI change vs NDVI (period 1) for the (d) pink first quadrant, (e) yellow second quadrant, (f) light blue third quadrant, and (g) dark blue fourth quadrant [GIMMS scale; only significant NDVI exceeding std(NDVI) are selected].

3) The model does not consider the ground heat flux, which is a considerable component of Earth's surface energy budget in less vegetated mountainous regions (such as the Himalayas), because a decrease in vegetation cover reduces the difference between air and ground temperature, $\mathrm{Ta}-\mathrm{Ts}$. Thus ground heat flux increases in less vegetated regions when $\mathrm{Ta}>\mathrm{Ts}$ (see Wang et al. 2009). In this sense the observed vegetation increase (Fig. 5d) induces a ground heat flux reduction (G1 > G2). This needs to be considered when applying the ecohydrological Ansatz in semidesert areas $[\mathrm{U} 1=H /(N-\mathrm{G} 1)>\mathrm{U} 2=H /(N-\mathrm{G} 2)]$, which attributes the Himalayan mountainous areas as external (dark blue fourth quadrant). This shows that NDVI greenness information can be vital for interpreting the attribution analysis in this framework.

\section{Conclusions and outlook}

Ecohydrological states and their changes are suitably characterized by distributions and trajectories in a surface climate state space spanned by supplies of energy versus water. Ecohydrological dynamics is represented by trajectories in $(U, W)$ space, which attribute the causes of change to 1) climate impact (in terms of precipitation and net radiation) as external forcing and 2) internal processes (induced by anthropogenic activities) that modify the partitioning of the related surface fluxes. The Budyko framework-based biophysical underpinnings are measured by dryness $D=(1-W) /(1-U)$ and associated with the dominant climatic trend of increasing precipitation. An additional variable such as vegetation greenness embedded into the $(U, W)$ space may be viewed as an active tracer which, following ecohydrological trajectories, is linked with their attributions of change to external/climate and internal/human-induced effects. This attribution depends on the trajectories that, projected onto the $(U, W)$ plane, tend toward one quadrant (out of four, bounded by positive/negative main diagonals), thus providing the attribution to external or internal causes with enhanced or reduced aridity. Ecohydrological state space analysis applied to the geographically and climatically complex Tibetan Plateau region shows the following results:

1) The Budyko framework of analysis defines vegetation types (tundra, forest, grass, semidesert, and desert) associated with a long time scale and adapting climate variability. A global-scale analysis (Cai et al. 2014a) has demonstrated this jointly with the greenness index NDVI being sensitive to climate variability. In contrast, NDVI greenness is more sensitive to climate variability, hence responding on shorter time scales 
TABLE 1. Greenness vegetation (NDVI) decrease and increase (in percent) associated with the geographical location of ecohydrological change attributed to external and internal effects: (left) entire Tibetan Plateau and (right) significant areas where $(W, U)$ changes exceed $\operatorname{std}(W)$ or $\operatorname{std}(U)$.

\begin{tabular}{ccccc}
\hline \hline \multirow{2}{*}{$\begin{array}{c}\text { Vegetation (NDVI) } \\
\text { region }\end{array}$} & \multicolumn{4}{c}{ Attribution (\%) } \\
\cline { 2 - 5 } & \multicolumn{2}{c}{ Entire } & \multicolumn{2}{c}{ Significant } \\
\hline & External & Internal & External & Internal \\
Increase & 3.8 & 7.7 & 2.0 & 8.5 \\
Decrease & 3.1 & 7.0 & 0.6 & 7.7 \\
& Internal & External & Internal & External \\
Increase & 8.4 & 41.4 & 7.2 & 44.1 \\
Decrease & 4.8 & 23.8 & 6.8 & 23.1 \\
\hline
\end{tabular}

superimposed by seasonal cycles. A regional-scale analysis of change focusing on the Tibetan Plateau is presented in this paper. Although classes of vegetation are limited to mainly grass, NDVI is sufficiently sensitive to capture changes within one type (grass).

2) External climate change toward wetter conditions on the Tibetan Plateau controls vegetation dynamics, especially in permafrost regions. Apparent effects of internal anthropogenic processes are detected in regions of relatively high population density and growth.

3) Areas with water surplus (increasing $W$ ) benefit most from climate change (showing vegetation greenness growth). But the relation with energy surplus (or $U$ ) change is not unambiguous. Ecohydrological diagnostics attributes high mountainous regions (such as the Himalayas) as internal without considering heat storage deficit (and possibly decreasing albedo) due to increasing vegetation.

The results obtained and methodologies applied are relevant for regional near-surface climate diagnostics 1) to analyze distributions and their change in phase space rather than first or second moments of gridpoint or single station variability in geographical space and 2) to estimate their attribution of change inducing processes to external (or climate induced) or internal (or anthropogenic) sources. Further research on measures of a multiscale resilience along the rainfall-runoff chain is beyond the scope of this analysis.

Acknowledgments. Support by the Chinese Science Database (XXH12504-1-12) and by the Max Planck Fellow Group (DC, KF), and the hospitality of the KlimaCampus, University of Hamburg, and referees' comments, are all acknowledged.

\section{REFERENCES}

An, Z., J. E. Kutzbach, W. L. Prell, and S. C. Porter, 2001: Evolution of Asian monsoons and phased uplift of the Himalaya-Tibetan plateau since Late Miocene times. Nature, 411, 62-66, doi:10.1038/ 35075035 .

Balsamo, G., and Coauthors, 2012: ERA-Interim/Land: A global land-surface reanalysis based on ERA-Interim meteorological forcing. ERA Rep. Series 13, 25 pp. [Available online at http:// old.ecmwf.int/publications/library/ecpublications/_pdf/era/ era_report_series/RS_13.pdf.]

Barichivich, J., K. R. Briffa, R. B. Myneni, T. J. Osborn, T. M. Melvin, P. Ciais, S. Piao, and C. Tucker, 2013: Large-scale variations in the vegetation growing season and annual cycle of atmospheric $\mathrm{CO}_{2}$ at high northern latitudes from 1950 to 2011. Global Change Biol., 19, 3167-3183, doi:10.1111/gcb.12283.

Barr, A., T. A. Black, and H. McCaughey, 2009: Climatic and phenological controls of the carbon and energy balances of three contrasting boreal forest ecosystems in western Canada. Phenology of Ecosystem Processes, A. Noormets, Ed., Springer, 3-34.

Budyko, M., 1974: Climate and Life. Vol. 18, International Geophysics Series, Academic Press, 508 pp.

Burrows, M. T., and Coauthors, 2011: The pace of shifting climate in marine and terrestrial ecosystems. Science, 334, 652-655, doi:10.1126/science.1210288.

Cai, D., K. Fraedrich, F. Sielmann, Y. Guan, S. Guo, L. Zhang, and X. Zhu, 2014a: Climate and vegetation: An ERA-Interim and GIMMS NDVI analysis. J. Climate, 27, 5111-5118, doi:10.1175/JCLI-D-13-00674.1.

_ , Y. Guan, S. Guo, C. Zhang, and K. Fraedrich, 2014b: Mapping plant functional types over broad mountainous regions: A hierarchical soft time-space classification applied to the Tibetan Plateau. Remote Sens., 6, 3511-3532, doi:10.3390/rs6043511.

Chen, B., X. Zhang, J. Tao, J. Wu, J. Wang, P. Shi, Y. Zhang, and C. Yu, 2014: The impact of climate change and anthropogenic activities on alpine grassland over the Qinghai-Tibet Plateau. Agric. For. Meteor., 189-190, 11-18, doi:10.1016/ j.agrformet.2014.01.002.

Cong, N., T. Wang, H. Nan, Y. Ma, X. Wang, R. B. Myneni, and S. Piao, 2013: Changes in satellite-derived spring vegetation green-up date and its linkage to climate in China from 1982 to 2010: A multimethod analysis. Global Change Biol., 19, 881891, doi:10.1111/gcb.12077.

Duan, A., and G. Wu, 2008: Weakening trend in the atmospheric heat source over the Tibetan Plateau during recent decades. Part I: Observations. J. Climate, 21, 3149-3164, doi:10.1175/ 2007JCLI1912.1.

Goulden, M., and Coauthors, 1998: Sensitivity of boreal forest carbon balance to soil thaw. Science, 279, 214-217, doi:10.1126/ science.279.5348.214.

Hu, G., Z. Dong, J. Lu, and C. Yan, 2012: Driving forces of land use and land cover change (LUCC) in the Zoige Wetland, Qinghai-Tibetan Plateau. Sci. Cold Arid Reg., 4, 422-430.

Kang, S. C., Y. W. Xu, Q. L. You, W. A. Flügel, N. Pepin, and T. D. Yao, 2010: Review of climate and cryospheric change in the Tibetan Plateau. Environ. Res. Lett., 5, 015101, doi:10.1088/ 1748-9326/5/1/015101.

Keeling, C. D., J. Chin, and T. Whorf, 1996: Increased activity of northern vegetation inferred from atmospheric $\mathrm{CO}_{2}$ measurements. Nature, 382, 146-149, doi:10.1038/382146a0.

Milne, B., V. Gupta, and C. Restrepo, 2002: A scale invariant coupling of plants, water, energy, and terrain. Ecoscience, 9, 191-199.

Myneni, R. B., C. Keeling, C. Tucker, G. Asrar, and R. Nemani, 1997: Increased plant growth in the northern high latitudes from 1981 to 1991. Nature, 386, 698-702, doi:10.1038/386698a0. 
Nemani, R. R., C. D. Keeling, H. Hashimoto, W. M. Jolly, S. C. Piper, C. J. Tucker, R. B. Myneni, and S. W. Running, 2003: Climate-driven increases in global terrestrial net primary production from 1982 to 1999. Science, 300, 1560-1563, doi:10.1126/ science. 1082750 .

Panday, P. K., and B. Ghimire, 2012: Time-series analysis of NDVI from AVHRR data over the Hindu Kush-Himalayan region for the period 1982-2006. Int. J. Remote Sens., 33, 6710-6721, doi:10.1080/01431161.2012.692836.

Peñuelas, J., T. Rutishauser, and I. Filella, 2009: Phenology feedbacks on climate change. Science, 324, 887-888, doi:10.1126/ science.1173004.

Piao, S., J. Fang, L. Zhou, Q. Guo, M. Henderson, W. Ji, and S. Tao, 2003: Interannual variations of monthly and seasonal normalized difference vegetation index (NDVI) in China from 1982 to 1999. J. Geophys. Res., 108, 4401, doi:10.1029/ 2002JD002848.

Renner, M., R. Seppelt, and C. Bernhofer, 2012: Evaluation of water-energy balance frameworks to predict the sensitivity of streamflow to climate change. Hydrol. Earth Syst. Sci., 16, 1419-1433, doi:10.5194/hess-16-1419-2012.

Richardson, A. D., and Coauthors, 2010: Influence of spring and autumn phenological transitions on forest ecosystem productivity. Philos. Trans. Roy. Soc., 365B, 3227-3246, doi:10.1098/rstb.2010.0102.

Serra, P., X. Pons, and D. Saurí, 2008: Land-cover and land-use change in a Mediterranean landscape: A spatial analysis of driving forces integrating biophysical and human factors. Appl. Geogr., 28, 189-209, doi:10.1016/j.apgeog.2008.02.001.

Tomer, M. D., and K. E. Schilling, 2009: A simple approach to distinguish land-use and climate-change effects on watershed hydrology. J. Hydrol., 376, 24-33, doi:10.1016/ j.jhydrol.2009.07.029.

Tucker, C. J., J. E. Pinzon, M. E. Brown, D. Slayback, E. W. Pak, R. Mahoney, E. Vermote, and N. El Saleous, 2005: An extended AVHRR 8-km NDVI data set compatible with MODIS and SPOT vegetation NDVI data. Int. J. Remote Sens., 26, 44854498, doi:10.1080/01431160500168686.

Wang, D., and M. Hejazi, 2011: Quantifying the relative contribution of the climate and direct human impacts on mean annual streamflow in the contiguous United States. Water Resour. Res., 47, W00J12, doi:10.1029/2010WR010283.

Wang, G., H. Hongchang, L. Guangsheng, and L. Na, 2009: Impacts of changes in vegetation cover on soil water heat coupling in an alpine meadow of the Qinghai-Tibet Plateau,
China. Hydrol. Earth Syst. Sci., 13, 327-341, doi: 10.5194/ hess-13-327-2009.

Wang, H., D. Liu, H. Lin, A. Montenegro, and X. Zhu, 2015: NDVI and vegetation phenology dynamics under the influence of sunshine duration on the Tibetan plateau. Int. J. Climatol., 35, 687-698, doi: 10.1002/joc.4013.

Wang, Q., 2009: Prevention of Tibetan eco-environmental degradation caused by traditional use of biomass. Renew. Sustain. Energy Rev., 13, 2562-2570, doi:10.1016/j.rser.2009.06.013.

Wang, X., D. Zheng, and Y. Shen, 2008: Land use change and its driving forces on the Tibetan Plateau during 1990-2000. Catena, 72, 56-66, doi:10.1016/j.catena.2007.04.003.

Wu, T., L. Zhao, R. Li, Q. Wang, C. Xie, and Q. Pang, 2013: Recent ground surface warming and its effects on permafrost on the central Qinghai-Tibet Plateau. Int. J. Climatol., 33, 920-930, doi:10.1002/joc.3479.

Yang, K., B. Ye, D. Zhou, B. Wu, T. Foken, J. Qin, and Z. Zhou, 2011: 2011: Response of hydrological cycle to recent climate changes in the Tibetan Plateau. Climatic Change, 109, 517534, doi:10.1007/s10584-011-0099-4.

Yao, T., Z. Li, L. G. Thompson, E. Mosley-Thompson, Y. Wang, L. Tian, N. Wang, and K. Duan, 2006: $\delta^{18} \mathrm{O}$ records from Tibetan ice cores reveal differences in climatic change. Ann. Glaciol., 43, 1-7, doi:10.3189/172756406781812131.

— , and Coauthors, 2012: Third Pole Environment (TPE). Environ. Dev., 3, 52-64, doi:10.1016/j.envdev.2012.04.002.

You, Q., S. Kang, W.-A. Flügel, A. Sanchez-Lorenzo, Y. Yan, J. Huang, and J. Martin-Vide, 2010: From brightening to dimming in sunshine duration over the eastern and central Tibetan Plateau (1961-2005). Theor. Appl. Climatol., 101, 445-457, doi:10.1007/s00704-009-0231-9.

_- A. Sanchez-Lorenzo, M. Wild, D. Folini, K. Fraedrich, G. Ren, and S. Kang, 2013: Decadal variation of surface solar radiation in the Tibetan Plateau from observations, reanalysis and model simulations. Climate Dyn., 40, 2073-2086, doi:10.1007/s00382-012-1383-3.

Zhang, L., W. Dawes, and G. Walker, 2001: Response of mean annual evapotranspiration to vegetation changes at catchment scale. Water Resour. Res., 37, 701-708, doi:10.1029/2000WR900325.

Zhu, X., O. Bothe, and K. Fraedrich, 2011: Summer atmospheric bridging between Europe and East Asia: Influences on drought and wetness on the Tibetan Plateau. Quat. Int., 236, 151-157, doi:10.1016/j.quaint.2010.06.015.

_ - W. Wang, and K. Fraedrich, 2013: Future climate in the Tibetan Plateau from a statistical regional climate model. J. Climate, 26, 10125-10 138, doi:10.1175/JCLI-D-13-00187.1. 